\title{
Enhanced oral bioavailability of nevirapine within micellar nanocarriers compared with Viramune ${ }^{\circledR}$
}

\author{
Marcela A. Moretton ${ }^{\mathrm{a}}$, Laura Cohen ${ }^{\mathrm{b}}$, Leandro Lepera ${ }^{\mathrm{a}}$, Ezequiel Bernabeu ${ }^{\mathrm{a}}$, \\ Carlos Taira $^{\mathrm{b}, \mathrm{c}}$, Christian Höcht ${ }^{\mathrm{b}}$, Diego A. Chiappetta ${ }^{\mathrm{a}, \mathrm{c}, *}$ \\ a Department of Pharmaceutical Technology, Faculty of Pharmacy and Biochemistry, University of Buenos Aires, Argentina \\ ${ }^{\mathrm{b}}$ Department of Pharmacology, Faculty of Pharmacy and Biochemistry, University of Buenos Aires, Argentina \\ ${ }^{\mathrm{c}}$ National Science Research Council (CONICET), Argentina
}

\section{A R T I C L E I N F O}

\section{Article history:}

Received 4 April 2014

Received in revised form 25 May 2014

Accepted 20 June 2014

Available online 28 June 2014

\section{Keywords:}

Polymeric micelles

PEO-PPO-PEO block copolymers

Nevirapine

In vivo oral pharmacokinetic studies

Viramune $^{\circledR}$

\begin{abstract}
A B S T R A C T
In this work, Nevirapine (NVP) was encapsulated within three derivatives of poly(ethylene oxide)-poly(propylene oxide)-poly(ethylene oxide) (PEO-PPO-PEO) block copolymers (Tetronic ${ }^{\circledR} 904$, 1107 and Pluronic ${ }^{\circledR}$ F127) with and without the addition of three pharmaceutical cosolvents (glycerin, propylene glycol and polyethylene glycol 400$)$ over a wider range of concentrations $(0-40 \% \mathrm{v} / \mathrm{v})$. Also, we evaluated the effect of addition of the cosolvents on the micellar size as determined by dynamic light scattering (DLS) measurements and transmission electron microscopy (TEM). The solubilization capacity of the systems was investigated by UV-spectrophotometry $(282 \mathrm{~nm})$ and the systems stability was evaluated for 1 month at $25^{\circ}$ C. Finally, oral bioavailability of the NVP-loaded micellar systems $(2 \mathrm{mg} / \mathrm{mL})$ was assessed in male Wistar rats $(8 \mathrm{mg} / \mathrm{kg})$ and compared with a pediatric commercially available formulation (Viramune ${ }^{\circledR}$ ). The present study demonstrates that PEO-PPO-PEO polymeric micelles were able to enhance apparent aqueous solubility of NVP with the addition of cosolvents. Moreover, micellar nanocarriers significantly $(p<0.05)$ improved the oral bioavailability of the drug versus Viramune ${ }^{\circledR}$.

Overall results support the suitability of the strategy toward the development of an optimized NVP aqueous formulation to prevent HIV/AIDS mother-to-child transmission.
\end{abstract}

(ㄷ) 2014 Elsevier B.V. All rights reserved.

\section{Introduction}

The last reports on the Human Immunodeficiency Virus (HIV)/Acquired Immunodeficiency Syndrome (AIDS) scourge indicate that worldwide more than 36 million people live with the infection [1]. HIV can be transmitted from a mother to her child during pregnancy, labor, delivery and later by breastfeeding [2]. Prevention of mother-to-child transmission of HIV is one of the most important activities worldwide since 1998 [3]. Today, pediatric HIV has been almost eliminated in developed countries but, unfortunately, the situation is different in developing countries [4]. In 2011, around 330,000 infants became infected with HIV and an estimated 230,000 died from AIDS. This translates to 900 new infections in children each day, the majority of which occur in sub-Saharan Africa. Most of these infections were as a result of

\footnotetext{
* Corresponding author at: Department of Pharmaceutical Technology, Faculty of Pharmacy and Biochemistry, University of Buenos Aires, 956 Junín Street, 6th Floor, Buenos Aires CP1113, Argentina. Tel.: +54 114964 8271; fax: +54 1149648271.

E-mail address: diegochiappetta@yahoo.com.ar (D.A. Chiappetta).
}

mother-to-child transmission [5]. These numbers can be reduced $(<5 \%)$ taking a regimen of antiretrovirals (ARVs) to decrease the mother-to-child transmission [6]. In case of infants, the World Health Organization (WHO) recommends, in one of their options, that children should receive nevirapine (NVP) oral daily for at least 6 weeks if the mother take ARVs for her own health [7]. The treatment consists of a single dose NVP at birth ( $2 \mathrm{mg} / \mathrm{kg}$ ) plus NVP daily ( $5 \mathrm{mg} / \mathrm{d}$ ) until 6 weeks age [8]. Without treatment, the $50 \%$ of the children die before the 2-years-old [9].

The gastrointestinal absorption of drugs in children is very different from that in adults. The gastric $\mathrm{pH}$ is rather neutral in neonates due to the presence of amniotic fluid and then it became acidic after removal of the gastric contents [10]. Besides during the first 2 years of life the gastric $\mathrm{pH}$ of children is high compared with adults [11].

NVP is a lipophilic non-nucleoside reverse transcriptase inhibitor and it belongs to class II of the Biopharmaceutics Classification System [12]. It is practically insoluble in water $(\sim 0.1 \mathrm{mg} / \mathrm{mL})$ with a $\mathrm{p} K_{\mathrm{a}}$ of 2.8 , which gives $\mathrm{pH}$ dependent solubility [13]. For this reason, the dissolution of the drug has been considered to be the rate-limiting step for absorption [14]. 
The drug is marketed as tablet or oral suspension dosage form, being the suspension the only pediatric formulation available. NVP oral suspension is very viscous, making it difficult to administer with a medicine cup or spoon the small doses required for infants [15]. This property increases the potential for dosage errors, and complicates treatment adherence. Furthermore, unlike the solutions, the suspensions need to be shaken, previous administration, to ensure content uniformity [16].

In general, there is a good correlation between increased solubility and improved bioavailability for class II drugs. Very few attempts have been reported in the literature to water-solubilize NVP using different carriers for oral administration. Some authors investigated the complexation of NVP with different types of $\beta$ cyclodextrins to overcome the drawbacks associated with the drug [17-19]. Chudasama et al. [20], prepare a self-emulsifying drug delivery system to improve the solubility and the intestinal absorption of NVP. None of them evaluated the drug delivery systems in vivo.

Encapsulation of lipophilic drugs within the hydrophobic core of polymeric micelles is one of the most attractive nanotechnological strategies to improve the aqueous solubility and oral bioavailability of some drugs [21-23]. Polymeric micelles are nanoscopic structures formed by amphiphilic block copolymers composed of hydrophilic and hydrophobic moieties. These macromolecules self-aggregate in aqueous media, above a certain concentration denominated critical micelle concentration (CMC) [24]. Two of the copolymers most extensively studied as drug delivery vehicles due to their surfactant abilities and low toxicity are derivatives of poly(ethylene oxide)-poly(propylene oxide)-poly(ethylene oxide) (PEO-PPO-PEO) block copolymers known as poloxamers (Pluronic $^{\circledR}$ ) for the linear version, and poloxamines (Tetronic ${ }^{\circledR}$ ) for the X-shaped polymers [25,26]. Also, the poloxamines present an ethylene diamine central group that provides $\mathrm{pH}$ and temperature-responsive micellization properties [27]. The solubility of NVP in some non-ionic surfactants as polyoxyethylene alkyl ethers and polyoxyethylene sorbitan fatty acid esters is ranged between 1 and $2.7 \mathrm{mg} / \mathrm{mL}$ [20]. Although this solubility values are clinically relevant, one attractive alternative is the addition of pharmaceutical cosolvents to improve the performance of micellar dispersions on drug solubilization.

In this work, we studied the solubilization capacity of three derivatives of PEO-PPO-PEO block copolymers (Tetronic ${ }^{\circledR} 904$, 1107 and Pluronic ${ }^{\circledR}$ F127) with and without the addition of three cosolvents of pharmaceutical interest (glycerin, propylene glycol and polyethylene glycol 400) over a wider range of concentrations for NVP. Also, we evaluated the effect of addition of the solvents on the micellar size as determined by dynamic light scattering (DLS) measurements. Finally, the micellar nanocarriers were evaluated in vivo versus the pediatric commercially available formulation (Viramune ${ }^{\circledR}$ ) and an extemporaneous NVP suspension.

\section{Experimental}

\subsection{Materials}

Nevirapine (NVP) was purchased from LKM Pharmaceutical Laboratories, Buenos Aires, Argentina, poloxamines Tetronic ${ }^{\circledR} 904$ (T904, $\left.M_{\mathrm{W}} 6.7 \mathrm{kDa}\right)$ and 1107 (T1107, $\left.M_{\mathrm{W}} 15 \mathrm{kDa}\right)$, and poloxamer Pluronic $^{\circledR}$ F127 $\left(M_{\mathrm{W}} 12.6 \mathrm{kDa}\right)$ were a gift from BASF (NJ, USA). Glycerin (Gly), propylene glycol (PG) and polyethylene glycol 400 (PEG400) were purchased from Parafarm ${ }^{\circledR}$, Buenos Aires, Argentina. Clinical formulation Viramune ${ }^{\circledR}$ was supplied by Boehringer Ingelheim S.A., Argentina. Other reagents and solvents of analytical and HPLC grade were used as received.

\subsection{Critical micellar concentration determination}

The critical micellar concentration (CMC) of T904, T1107 and F127, without and with the addition of the three cosolvents (20\% and $40 \% \mathrm{v} / \mathrm{v}$ ) at $25^{\circ} \mathrm{C} \pm 0.5^{\circ} \mathrm{C}$ was determined by means of surface tension using the du Nöuy ring method (Fernández Berlusconi y Rocca SRL, Argentina).

\subsection{Preparation of polymeric micelles}

Polymeric micelles (10\% final polymer concentration, expressed in weight per volume) were prepared by dissolving the required amount of copolymer in water at $4{ }^{\circ} \mathrm{C}$. The micelles with the different cosolvents were prepared dissolving the copolymer with the addition of water and different concentrations of cosolvents ( $0-40 \%$ $\mathrm{v} / \mathrm{v}$ ). Then, the micelles were equilibrated at $25^{\circ} \mathrm{C}$ for $24 \mathrm{~h}$ before the assays.

\subsection{Measurement of micellar size and size distribution}

The size and size distribution of drug-free polymeric micelles were measured by Dynamic Light Scattering (DLS, Zetasizer NanoZs, Malvern Instruments, Worcestershire, UK) provided with a $4 \mathrm{~mW}$ He-Ne $(633 \mathrm{~nm})$ laser and a digital correlator ZEN3600. Measurements were conducted at a scattering angle of $\theta=173^{\circ}$ to the incident beam. Samples were filtered by clarifying filters $(0.45 \mu \mathrm{m}$, cellulose nitrate) and equilibrated at $25^{\circ} \mathrm{C}$. Previously, the instrument was calibrated with standard latex nanoparticles provided by Malvern Instruments, UK. Results of hydrodynamic diameter (Dh) and polydispersity index (PDI) are expressed as the average of at least three measurements.

\subsection{Visualization of polymeric micelles using transmission electron microscopy (TEM)}

To evaluate the addition of cosolvents in the morphology and size of copolymeric micelles, we prepared poloxamine micelles (T904) in presence and absence of PEG400 (40\% v/v) and then they were studied by means of transmission electron microscopy (Philips CM-12 TEM apparatus, FEI Company, Eindhoven, The Netherlands). Samples $(5 \mu \mathrm{L})$ were placed onto a grid covered with Fomvar film. After $30 \mathrm{~s}$, the excess was carefully removed with filter paper and phosphotungstic acid $(2 \% \mathrm{w} / \mathrm{v}, 5 \mu \mathrm{L})$ was added. After $30 \mathrm{~s}$, the excess was removed and water $(5 \mu \mathrm{L})$ was added, left for $30 \mathrm{~s}$ and removed. Samples were finally dried in a closed container with silica gel and analyzed.

\subsection{Encapsulation of NVP}

NVP (in excess) was added to micellar suspensions $(5 \mathrm{~mL})$ and samples were placed under magnetic stirring $(72 \mathrm{~h})$ at $25^{\circ} \mathrm{C}$. The resulting suspensions were filtered $(0.45 \mu \mathrm{m}$, cellulose nitrate) to remove insoluble NVP. The drug concentration was determined by UV spectrophotometry (282 nm, CARY [1E] UV-Visible Spectrophotometer, Varian, Palo Alto, California) using a calibration curve of NVP ethanolic solutions $(8-50 \mu \mathrm{g} / \mathrm{mL})$. The correlation factor was 0.9967-1.0000. A drug-free copolymer ethanolic solution was used as blank. Solubility factors $(f s)$ were calculated according to the equation:

$f s=\frac{S_{a}}{S_{\text {water }}}$

where $S_{a}$ and $S_{\text {water }}$ being the NVP apparent solubility in micelles and the intrinsic solubility in water $(0.1 \mathrm{mg} / \mathrm{mL})$. The size and size distribution of the drug-loaded micelles was determined by DLS at $25^{\circ} \mathrm{C}$ (see above). 
To evaluate the physical stability of NVP-loaded micelles, samples were incubated at room temperature and the drug concentration was monitored over $28 \mathrm{~d}$ according to the procedure depicted above.

\subsection{Physicochemical stability of NVP-containing micelles upon dilution}

To determine the ability to withstand dilution of drug-loaded micelles in the gastrointestinal environment, 10\% T904 micelles with PG and PEG400 (1:1) 40\% v/v and 10\% F127 micelles with the same mixture of cosolvents loaded with NVP $(2 \mathrm{mg} / \mathrm{mL})$ were diluted (1:10 and 1:50) in two different media (i) $\mathrm{HCl} 0.1 \mathrm{~N}, \mathrm{pH} 1.2$ and (ii) phosphate buffer pH 6.8 USP 30 [28], incubated at $37^{\circ} \mathrm{C}$ and the drug concentration monitored over time by UV spectrophotometry (see Section 2.6).

\subsection{In vitro NVP release}

To evaluate the drug-release profiles from the micelles, the two systems evaluated in the previous assay (Section 2.7) were placed into dialysis membranes (Spectra/Por ${ }^{\circledR}$ Dialysis Membrane, molecular weight cut off $=3,500$, nominal flat width $18 \mathrm{~mm}$, Rancho Dominguez, CA, USA) and immersed into the release medium $\left(50 \mathrm{~mL}\right.$ ) for $6 \mathrm{~h}$ at $37 \pm 0.5^{\circ} \mathrm{C}$ under gentle magnetic stirring (50 RPM). Release medium was composed of (i) $\mathrm{HCl} 0.1 \mathrm{~N}$ ( $\mathrm{pH} 1.2$ ) during the first $2 \mathrm{~h}$ and (ii) phosphate buffer USP 30 ( $\mathrm{pH} \mathrm{6.8)} \mathrm{with}$ Tween $801 \% \mathrm{v} / \mathrm{v}$ for the last $4 \mathrm{~h}$. At different time points $(0.5,1$, $2,3,4,5$ and $6 \mathrm{~h}$ ) aliquots were removed from the release medium and NVP concentration was determined by UV spectrophotometry at $313 \mathrm{~nm}$ and $282 \mathrm{~nm}$ for $\mathrm{HCl} 0.1 \mathrm{~N}$ and phosphate buffer, respectively. The linearity range was established between 0.00625 and $0.05 \mathrm{mg} / \mathrm{mL}\left(R^{2}: 0.9997-0.9999\right)$ in both external mediums. After every predetermined time interval, the total release medium was replaced with fresh medium to maintain sink conditions. Assays were carried out in triplicate and the results are expressed as mean \pm S.D.

\subsection{Oral pharmacokinetics}

The bioavailability of the NVP-loaded micellar system was assessed in male Wistar rats (220-250 g). Four NVP formulations ( $2 \mathrm{mg} / \mathrm{mL}$ ) were evaluated: NVP-loaded $10 \%$ T904 micelles with PG and PEG400 (1:1) 40\%v/v, NVP-loaded 10\% F127 micelles with the same mixture of cosolvents, a extemporaneous suspension prepared in $0.5 \%$ carboxymethylcellulose aqueous solution and finally, the commercially available suspension of NVP (Viramune $\left.{ }^{\circledR}\right)$. Animal experiments were performed in accordance with the 'Principles of laboratory animal care' (NIH publication No. 85-3, revised 1985). Animals were maintained on a 12-h light/dark cycle and kept in a room at $22 \pm 2{ }^{\circ} \mathrm{C}$ with the air adequately recycled. All animals received a standard rodent diet (Asociación Cooperativas Argentinas, Buenos Aires, Argentina) with the following composition (w/w): $20 \%$ proteins, 3\% fat, $2 \%$ fiber, $6 \%$ minerals, and $69 \%$ starch and vitamin supplements, containing the same amount of calories. Experiments were performed in rats fasted for $12 \mathrm{~h}(n=5$ for each group). Drug formulations were orally administered by gavage, where a stomach tube is inserted into the esophagus of conscious rats. The dose of NVP was $8 \mathrm{mg} / \mathrm{kg}$. After drug administration, blood samples $(70 \mu \mathrm{L})$ were obtained at $1,2,3,4,5,6,7$ and $24 \mathrm{~h}$ by tail vein collection, as described elsewhere [29]. Blood samples were centrifuged $\left(10,000 \mathrm{rpm}, 10 \mathrm{~min}, 4^{\circ} \mathrm{C}\right.$, MiniSpin ${ }^{\circledR}$ plusTM, Eppendorf AG, Germany) to collect the plasma. It is important to mention that blood sampling could alter pharmacokinetic and pharmacodynamic behavior of drugs due to fluid loss. In our experimental protocol, total blood volume extracted was approximately
$600 \mu \mathrm{L}$ during $24 \mathrm{~h}$. This volume is significantly lower than the maximal recommended $(3.5 \mathrm{~mL})$, and therefore we assume that the blood loss during our experimental protocol did not affect the pharmacokinetic properties of NVP. Plasma $(10 \mu \mathrm{L})$ was deproteinized with acetonitrile $(20 \mu \mathrm{L})$ and the concentration of the drug determined by HPLC.

\subsection{Chromatographic method for NVP analysis}

Plasma samples were determined by liquid chromatography (HPLC) using a Phenomenex Luna $5 \mu \mathrm{m}, \mathrm{C} 18,150 \mathrm{~mm} \times 4.60 \mathrm{~mm}$ column (Phenomenex, CA, USA) with a UV detector $(254 \mathrm{~nm}$, UVIS 204, Linear Instruments, Reno, USA). The mobile phase consisted in distilled water, methanol and acetonitrile (60:20:20), the flow rate was maintained at $1.2 \mathrm{~mL} / \mathrm{min}$ and the injection volume was $20 \mu \mathrm{L}$. The chromatographic method was validated for selectivity, linearity, precision and accuracy. Briefly, the linearity range for quantification was $20-5000 \mathrm{ng} / \mathrm{mL}\left(R^{2}: 0.9998-0.9999\right)$. The intraday and interday coefficients of variation were $4.6(n=6)$ and 6.9 $(n=18)$, respectively. The accuracy was evaluated in terms of recovery. The recovery was evaluated at three levels (high, medium and low) and the values were between $92.1 \%$ and $106.6 \%$.

\subsection{Evaluation of in vivo data}

Pharmacokinetic analysis was performed by using the TOPFIT program (version 2.0, Dr. Karl Thomae Gmbh, Schering AG, GödeckeAG, Germany). Non-compartment model was used to fit the data. The following data was calculated: area under the curve between 0 and $24 \mathrm{~h}\left(\mathrm{AUC}_{0-24}\right)$, maximum plasma concentration $\left(C_{\max }\right)$, time to maximum plasma concentration $\left(t_{\max }\right)$ and plasma elimination half-life $\left(t_{1} / 2\right)$. Statistical analysis was performed using GraphPad Prism version 5.02 for Windows ${ }^{\circledR}\left(\right.$ GraphPad $^{\circledR}$ Software, San Diego, CA, USA).

Pharmacokinetic parameters were log transformed for statistical analysis in order to reduce heterogeneity of the variance, and further compared by one-way analysis of variance and the Bonferroni post hoc test. Statistical significance was defined as $p<0.05$.

The relative oral bioavailability $\left(F_{r}\right)$ was calculated by taking the ratio between the $\mathrm{AUC}_{0-24}$ of each micellar system or Viramune ${ }^{\circledR}$ and the NVP extemporaneous suspension (reference) when the administered doses were identical

$F_{r}(\%)=\frac{\mathrm{AUC}_{\mathrm{T}}}{\mathrm{AUC}_{\mathrm{R}}} \times 100$

$A U C_{T}$ and $A U C_{R}$ being the $A U C_{0-24}$ of the tested (T) sample and the reference $(R)$, respectively.

\section{Results and discussion}

\section{1. $C M C$}

Amphiphilic molecules tend to associate into micellar systems as a spontaneous process in aqueous solution. The poloxamine and poloxamer micelles consist of a desolvated PPO core and a solvated PEO corona. In our case, the cmc was established as the copolymer concentration above which the surface tension showed a less pronounced change, indicating the formation of micelles. The $\mathrm{cmc}$ values obtained for the three copolymers assayed were $1.46 \%, 5.00 \%$ and $0.62 \% \mathrm{w} / \mathrm{v}$ for T904, T1107 and F127, respectively (Table 1). Interestingly, different environmental features have been proposed as a one of the main factors which could control micelle morphology and cmc [24]. In our study, the addition of water-miscible additives to the aqueous solution could modify the cmc due to the interaction of the cosolvent with both (i) the PEO corona and (ii) the aqueous media [30]. Results demonstrated that the addition of the three 
Table 1

Critical micellar concentration (CMC) values of copolymers (T904, T1107, F127) in aqueous solution without and with the addition of hydrophilic cosolvents (20\% and $40 \% \mathrm{v} / \mathrm{v}$ ) at $25^{\circ} \mathrm{C}$

\begin{tabular}{lllll}
\hline \multirow{2}{*}{ Cosolvent } & $\%(\mathrm{v} / \mathrm{v})$ & & \multicolumn{2}{l}{$\mathrm{CMC}^{\mathrm{a}}(\% \mathrm{w} / \mathrm{v})$} \\
\cline { 3 - 5 } & & $\mathrm{T} 904$ & $\mathrm{~T} 1107$ & $\mathrm{~F} 127$ \\
\hline- & - & 1.46 & 5.00 & 0.62 \\
\multirow{2}{*}{ Gly } & 20 & 0.31 & 1.59 & 0.45 \\
& 40 & 0.01 & 0.90 & 0.23 \\
PG & 20 & 0.18 & 1.15 & 0.13 \\
\multirow{2}{*}{ PEG400 } & 40 & 0.13 & 0.94 & 0.12 \\
& 20 & 0.91 & 0.51 & 0.09 \\
\hline
\end{tabular}

a $\mathrm{CMC}$ values are determined by surface tension.

hydrophilic cosolvents (Gly, PG and PEG400) to the micellar solutions produced a decreased in the cmc values of each copolymer (T904, T1107 and F127), regardless the cosolvent assayed (Table 1). For example, the addition of Gly $20 \% \mathrm{v} / \mathrm{v}$ decreased the cmc value of T904 from $1.46 \% \mathrm{w} / \mathrm{v}$ to $0.31 \% \mathrm{w} / \mathrm{v}$, of $\mathrm{T} 1307$ from $5.00 \% \mathrm{w} / \mathrm{v}$ to $1.59 \% \mathrm{w} / \mathrm{v}$, and that of $\mathrm{F} 127$ from $0.62 \% \mathrm{w} / \mathrm{v}$ to $0.45 \% \mathrm{w} / \mathrm{v}$. A similar effect was observed with PG and PEG400 (Table 1). The shift of cmc values to lower copolymer concentrations denotes that the hydrophilic cosolvents favor the micellization process in comparison with distilled water. These results can be related to the hydrophilic nature of the cosolvents used in this study. Due to the cosolvent-water interactions, there is a reduction in available water to solvate PEO-PPO-PEO molecules. Therefore Gly, PG and PEG400 favor the formation of the micelles through dehydration of the PEO-PPO interface and a decrease on cmc is observed. This effect was more pronounced as the cosolvent concentration was increased $(40 \% \mathrm{v} / \mathrm{v})$ (Table 1$)$.

Interestingly, the cosolvent efficacy for decrease the cmc values for each copolymer employed could be related with the ratio hydrophilic/hydrophobic of them. In our case, T1107 and F127 are the copolymers more hydrophilic with a 70\% PEO content, while T904 is the most hydrophobic derivative with a 40\% PEO content [24]. In this way, results show that Gly $40 \% \mathrm{v} / \mathrm{v} /$ water mixture was more effective to decrease the cmc value of T904 (146-fold) than PG and PEG400 40\% v/v/water mixture (11.2- and 29.2-fold, respectively). In a similar manner, for those copolymers with the highest hydrophilic percentage (T1107 and F127), PEG400 40\% v/v/water mixture resulted more effective to decrease the $\mathrm{cmc}$ of both copolymers (55.6-fold and 8.9-fold, respectively) than the other cosolvents used. Since the octanol/water partition coefficients for Gly, PG and PEG400 are $-1.96,-0.92$ and -0.88 , respectively, Gly exhibits the greatest polarity followed by PG and PEG400 [31]. These results suggested that Gly/water mixture results in a better solvent for the surfactants with the highest hydrophilic content (T1107 and F127) being less effective for the micellization process. In a similar way, PEG400/water mixture results a better solvent for the copolymer with the lowest PEO-content (T904).

Overall, the addition of hydrophilic cosolvents to the micellar dispersions modified the aggregation pattern of the copolymers, promoting micellization at lower copolymer concentrations, being this effect more pronounced as the cosolvent concentration was increased. These results are in good concordance with previously investigations [30].

\subsection{Apparent hydrodynamic diameter}

The Dh and size distribution of the micelles were obtained by DLS using a copolymer concentration (10\%) well above the CMC in order to ensure that most of the copolymer chains are forming copolymeric micelles. To evaluate the effect of Gly, PG and PEG400 over copolymeric micelles, we studied the size variation without and with the addition of different cosolvent concentrations $(20 \%$, $30 \%$ and $40 \% \mathrm{v} / \mathrm{v}$ ). The log transformed intensity fraction distributions ( $\mathrm{Dh}$ ) obtained for the three copolymers without and with the cosolvents are illustrated in Fig. 1. Temperature was held at $25^{\circ} \mathrm{C}$, the same temperature used for the solubilization experiments. The addition of cosolvents to micellar solutions produces an increase in the micellar size. The intensity distributions shifted to higher values of $\log (\mathrm{Dh})$ as the concentration of three cosolvents were increased. For example, the addition of Gly, PG and PEG400 40\% $\mathrm{v} / \mathrm{v}$ on T904 micelles produced an increased from 10.2 to $41.4,40.2$ and $141.4 \mathrm{~nm}$, respectively (Fig. 1A-C). In the case of T1107 and F127, we observed a similar behavior; an increased in the cosolvents concentration produced a larger micellar size (Fig. 1D-I). In this case, T1107 micelles presented a bimodal size distribution with a main population of small structures $(5 \mathrm{~nm})$ and a secondary size fraction comprised of aggregates with $\mathrm{Dh}$ of $43 \mathrm{~nm}$. The addition of Gly produces an increased in the two size populations; for example, Gly $40 \% \mathrm{v} / \mathrm{v}$ increased the main population from 5 to $39 \mathrm{~nm}$ and the second one from 43 to $381 \mathrm{~nm}$ (Fig. 1D). With PG, we observed a similar phenomenon (Fig. 1E); where $40 \% \mathrm{v} / \mathrm{v}$ increased the size from 5 to $21 \mathrm{~nm}$ and from 43 to $158 \mathrm{~nm}$ for the main and the secondary population, respectively. Moreover, the addition of PEG400 produces a decreased in the size and the percentage of the first fraction and an increased in the second one; for example, PEG400 $40 \% \mathrm{v} / \mathrm{v}$ decreased the first population (lower percentage) from 5 to $2 \mathrm{~nm}$ and increased the second (higher percentage) from 43 to $108 \mathrm{~nm}$ (Fig. 1F). F127 micelles presented a bimodal size distribution with a small population of $5 \mathrm{~nm}$ and a principal fraction with $\mathrm{Dh}$ of $49 \mathrm{~nm}$. The addition of Gly produces the formation of a single population with an increased in the micellar size (Fig. 1G). By contrast, PG produces an increased in the two size populations; PG $40 \% \mathrm{v} / \mathrm{v}$ increased the first population (lower intensity) from 5 to $19 \mathrm{~nm}$ and the second (higher intensity) from 49 to $112 \mathrm{~nm}$ (Fig. 1H). Finally, the addition of PEG400 produces a similar effect that observed with T1107, from 5 to $2 \mathrm{~nm}$ for the first population (lower intensity) and from 49 to $164 \mathrm{~nm}$ for the second (higher intensity) (Fig. 1I). These results are in good concordance with previously investigations where the addition of different glycols produces an increased in the micellar size of ethylene and propylene oxide copolymers [32-34]. DLS measures the Dh, which includes the corona region with its associated solvent molecules, thus any changes in the corona will be reflected in the measured diameter. In our case, the Dh of the main population was increased as follows: PEG400 $>$ PG $>$ Gly. This behavior is due to the affinity of the cosolvents to water (Gly > PG > PEG400) [35]. The competition for water between the Gly and PEO blocks of the copolymer is much stronger in the case of Gly than in the case of PG and PEG400. The strong interaction Gly-water causes a reduction of the water available to solvate amphiphilic molecules [36]. Therefore, the smaller affinity of PEG400 to water favor and increase the water molecules associated to the micellar corona leading to a greater Dh value.

\subsection{Visualization of polymeric micelles using transmission electron microscopy (TEM)}

The spherical morphology and the effect of PEG400 (40\% v/v) in the T904 copolymeric micelles was confirmed by TEM analysis, as displayed in Fig. 2. The addition of the cosolvent produced clearly an increase in the size of copolymeric micelles (Fig. 2B) as we also observed in the DLS measurements. 

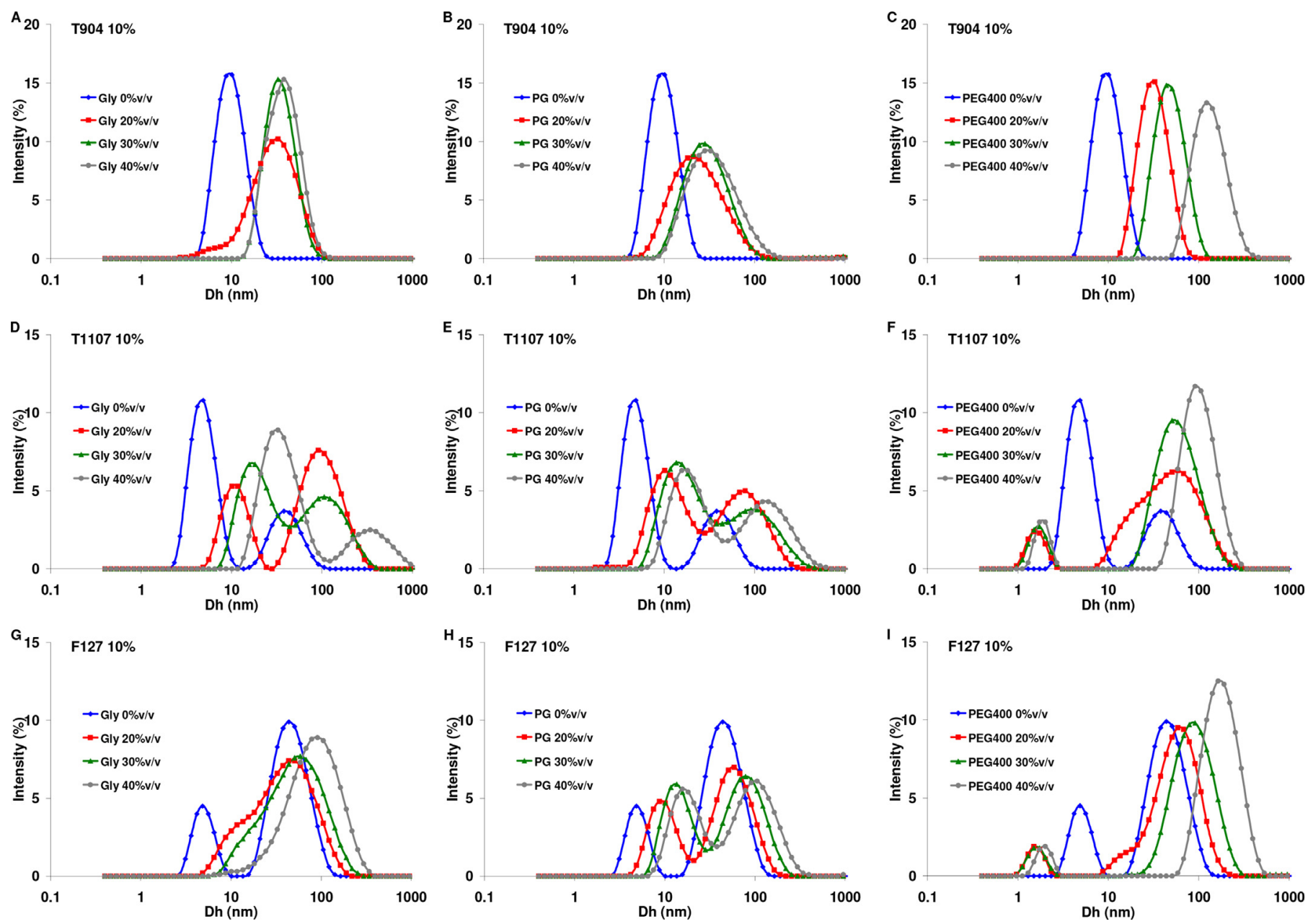

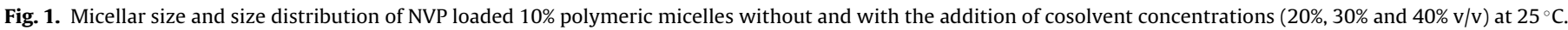

\subsection{Solubilization of NVP}

Solubility assays of NVP were carried out at a copolymer concentration $(10 \% \mathrm{w} / \mathrm{v})$ far above the CMC (Table 1$)$. This ensured the presence of copolymeric micelles. The values obtained for the solubility of NVP in aqueous solutions of the three copolymers at $25^{\circ} \mathrm{C}$, and also with the addition of cosolvents in the range of $10-40 \% \mathrm{v} / \mathrm{v}$ were presented in Table 2 . The solubilization of NVP was monitored using UV-spectroscopy. The increase of drug solubilized in the aqueous solutions was found in order T904 > F127 > T1107; being 4.3, 3.7 and 3.5 folds, respectively. This increase can be attributed to the fact that T904 is more hydrophobic than T1107 and F127. T904 presents a higher weight percent (wt\%) of PPO content ( $60 \%$ ), than T1107 and F127 ( 30\%). Probably, the high PPO content of T904 favors hydrophobic-hydrophobic interactions and drug solubilization. These results are in good concordance with previously investigations where copolymers with higher wt\% PPO content produces an increased in the solubilization of hydrophobic drugs [21,26,37,38]. As an approach to enhance the solubilization capacity of copolymeric micelles in a grater extend; we decided to add three cosolvents of pharmaceutical interest (Gly, PG and PEG400). The addition of cosolvents produced an increase on the solubility of NVP in the following order: PEG400 > PG > Gly (Table 2). For example, the addition of PEG400 40\% v/v to T904 increased the solubility to $2.35 \mathrm{mg} / \mathrm{mL}$, while PG and Gly reached to 1.99 and $0.78 \mathrm{mg} / \mathrm{mL}$, respectively. With T1107 and F127, we

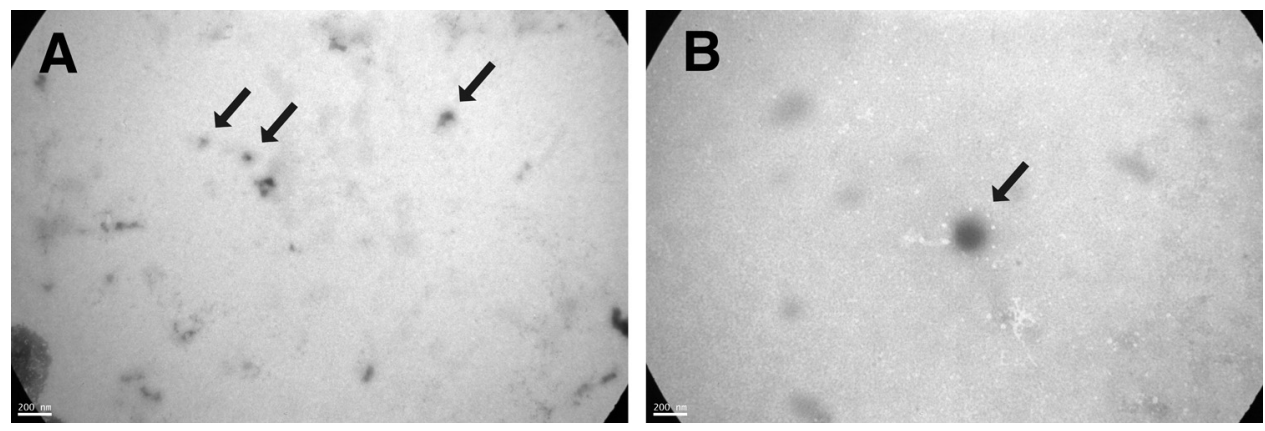

Fig. 2. TEM micrographs of T904 polymeric micelles (10\% w/v) prepared in water (A) and in PEG400 $40 \% \mathrm{v} / \mathrm{v}$ (B). Scale bar $=200 \mathrm{~nm}$. 
Table 2

Solubility of NVP in poloxamine and poloxamer micellar systems with different concentrations of cosolvents at $25^{\circ} \mathrm{C}$. Results are expressed as mean \pm S.D. ( $n=3$ ).

\begin{tabular}{|c|c|c|c|c|c|c|c|c|c|c|}
\hline \multirow[t]{2}{*}{ Cosolvent } & \multirow[t]{2}{*}{$\%(v / v)$} & \multirow{2}{*}{$\begin{array}{l}\text { Dielectric } \\
\text { constant }^{\mathrm{a}}\end{array}$} & \multicolumn{2}{|l|}{ Water } & \multicolumn{2}{|l|}{ T904 } & \multicolumn{2}{|l|}{ T1107 } & \multicolumn{2}{|l|}{ F127 } \\
\hline & & & Solubility (mg/mL) & $f s$ & Solubility (mg/mL) & $f_{S}$ & Solubility (mg/mL) & $f_{S}$ & Solubility $(\mathrm{mg} / \mathrm{mL})$ & fs \\
\hline- & - & 78.36 & $0.10 \pm 0.01$ & 1.0 & $0.43 \pm 0.04$ & 4.3 & $0.35 \pm 0.01$ & 3.5 & $0.37 \pm 0.01$ & 3.7 \\
\hline \multirow{4}{*}{ Gly } & 10 & 74.77 & $0.15 \pm 0.01$ & 1.5 & $0.51 \pm 0.02$ & 5.1 & $0.47 \pm 0.02$ & 4.7 & $0.47 \pm 0.01$ & 4.7 \\
\hline & 20 & 71.19 & $0.22 \pm 0.01$ & 2.2 & $0.61 \pm 0.01$ & 6.1 & $0.60 \pm 0.03$ & 6.0 & $0.58 \pm 0.01$ & 5.8 \\
\hline & 30 & 67.60 & $0.34 \pm 0.01$ & 3.4 & $0.77 \pm 0.02$ & 7.7 & $0.65 \pm 0.01$ & 6.5 & $0.67 \pm 0.01$ & 6.7 \\
\hline & 40 & 64.02 & $0.38 \pm 0.02$ & 3.8 & $0.78 \pm 0.01$ & 7.8 & $0.73 \pm 0.03$ & 7.3 & $0.72 \pm 0.01$ & 7.2 \\
\hline \multirow{4}{*}{ PG } & 10 & 73.72 & $0.20 \pm 0.01$ & 2.0 & $0.61 \pm 0.01$ & 6.1 & $0.60 \pm 0.06$ & 6.0 & $0.57 \pm 0.04$ & 5.7 \\
\hline & 20 & 69.09 & $0.40 \pm 0.01$ & 4.0 & $0.83 \pm 0.01$ & 8.3 & $0.89 \pm 0.02$ & 8.9 & $0.81 \pm 0.08$ & 8.1 \\
\hline & 30 & 64.45 & $0.70 \pm 0.05$ & 7.0 & $1.36 \pm 0.04$ & 13.6 & $1.23 \pm 0.02$ & 12.3 & $1.31 \pm 0.02$ & 13.1 \\
\hline & 40 & 59.82 & $1.00 \pm 0.01$ & 10.0 & $1.99 \pm 0.06$ & 19.9 & $1.88 \pm 0.03$ & 18.8 & $1.72 \pm 0.07$ & 17.2 \\
\hline \multirow{4}{*}{ PEG400 } & 10 & 71.76 & $0.27 \pm 0.01$ & 2.7 & $0.67 \pm 0.02$ & 6.7 & $0.68 \pm 0.01$ & 6.8 & $0.65 \pm 0.04$ & 6.5 \\
\hline & 20 & 65.17 & $0.58 \pm 0.02$ & 5.8 & $1.06 \pm 0.01$ & 10.6 & $1.02 \pm 0.06$ & 10.2 & $1.04 \pm 0.01$ & 10.4 \\
\hline & 30 & 58.57 & $0.85 \pm 0.03$ & 8.5 & $1.48 \pm 0.06$ & 14.8 & $1.58 \pm 0.04$ & 15.8 & $1.38 \pm 0.02$ & 13.8 \\
\hline & 40 & 51.98 & $1.44 \pm 0.05$ & 14.4 & $2.35 \pm 0.08$ & 23.5 & $2.43 \pm 0.06$ & 24.3 & $2.41 \pm 0.10$ & 24.1 \\
\hline PG:PEG400 (1:1) & 40 & - & $1.32 \pm 0.02$ & 13.2 & $2.36 \pm 0.10$ & 23.6 & $2.49 \pm 0.04$ & 24.9 & $2.45 \pm 0.16$ & 24.5 \\
\hline
\end{tabular}

$f s=$ solubility factor.

a Data taken from Ref. [37].

observed a similar behavior; where PEG400 40\% v/v increased the solubility to 2.43 and $2.41 \mathrm{mg} / \mathrm{mL}$, respectively. While PG reached to 1.88 and $1.72 \mathrm{mg} / \mathrm{mL}$, respectively. Finally, the addition of Gly $40 \% \mathrm{v} / \mathrm{v}$ only reached to 0.73 and $0.72 \mathrm{mg} / \mathrm{mL}$, respectively (Table 2). Without copolymer, also we observed an increase in the NVP solubility in the following order PEG400 > PG > Gly (Table 2). This behavior might be related to the dielectric constants of the cosolvent aqueous solutions (Table 2), which indicates that the solubility of NVP decreases with an increase in the polarity of these solutions. These results are in good concordance with previously investigations where an increase on hydrophobic drug solubility in different cosolvent aqueous solutions was observed (PEG400 > PG > Gly) [35,39]. Moreover, the higher solubility of NVP in PEG400 aqueous solutions is probably due to strong hydrophobic interactions.

Generally, the hydrophobic drug solubilization process in the PEO-PPO-PEO block copolymers is related to the formation of micelles stabilized by a corona of PEO-blocks with a hydrophobic core (PPO-blocks) [32,40].

To evaluate the solubilization capacity and effect of each cosolvent in the different systems we present in Fig. 3 the micellar solubilization capacity $\left(S-S_{0}\right)$ vs cosolvent concentration, where $\mathrm{S}$ is the solubility in the micellar systems with the addition of different cosolvent percentage $(0-40 \% \mathrm{v} / \mathrm{v})$ and $S_{0}$ is the solubility of NVP in water or in the corresponding cosolvent. The addition of Gly produces a minimal increase reaching a plateau quickly (Fig. 3A) with maximum values between 0.36 and $0.43 \mathrm{mg} / \mathrm{mL}$ for the three copolymers. Conversely, as the PG was increased, higher $S-S_{0}$ values were obtained (between 0.72 and $0.99 \mathrm{mg} / \mathrm{mL}$ ) (Fig. 3B). A similar behavior was observed with PEG400, where we attained values between 0.91 and $0.99 \mathrm{mg} / \mathrm{mL}$ (Fig. 3C). These results clearly confirm that PG and PEG400 were the cosolvents with higher effectiveness in the solubilization capacity of the systems.

A very important point in the pharmaceutical practice is to minimize the percentage of excipient needed to solubilize an effective amount of drug. For this reason, we prepared a micellar system optimized, in terms of NVP concentration and with the smallest possible percentage of cosolvents. To obtain a concentration of NVP $\geq 2 \mathrm{mg} / \mathrm{mL}$ (clinically useful) we used a mixture of PG and PEG400 ( $40 \% \mathrm{v} / \mathrm{v}$, ratio $1: 1$ ) due to these additives were the more effective to solubilize NVP. Surprisingly, these systems presented the best values of NVP solubility (Table 2 ).

Interestingly, we observed that the addition of cosolvents has a synergistic effect on the NVP solubilization from the micellar dispersions. Except Gly systems, all the samples displayed a greater solubilization extent than the corresponding theoretical mixture calculated as the sum of the amount of NVP solubilized in the pure micellar system and in the cosolvent solution. For example, T904 with PEG400 40\% v/v showed a solubility value of $2.35 \mathrm{mg} / \mathrm{mL}$ and the sum of the values corresponding to T904 and PEG400 40\% $\mathrm{v} / \mathrm{v}$ was $1.87 \mathrm{mg} / \mathrm{mL}$. Furthermore, T1107 and F127 with PEG400 $40 \% \mathrm{v} / \mathrm{v}$ showed values of 2.43 and $2.41 \mathrm{mg} / \mathrm{mL}$ as opposed to the corresponding sums of 1.79 and $1.81 \mathrm{mg} / \mathrm{mL}$. A similar behaviuor was observed for PG and with the cosolvent mixture (PG and PEG400). For example, T904 with PG:PEG400 (1:1) 40\%v/v showed solubility value of $2.36 \mathrm{mg} / \mathrm{mL}$ and the sum of the values corresponding to pure micellar system and cosolvent mixture was $1.75 \mathrm{mg} / \mathrm{mL}$. Similarly, T1107 and F127 with cosolvent mixture
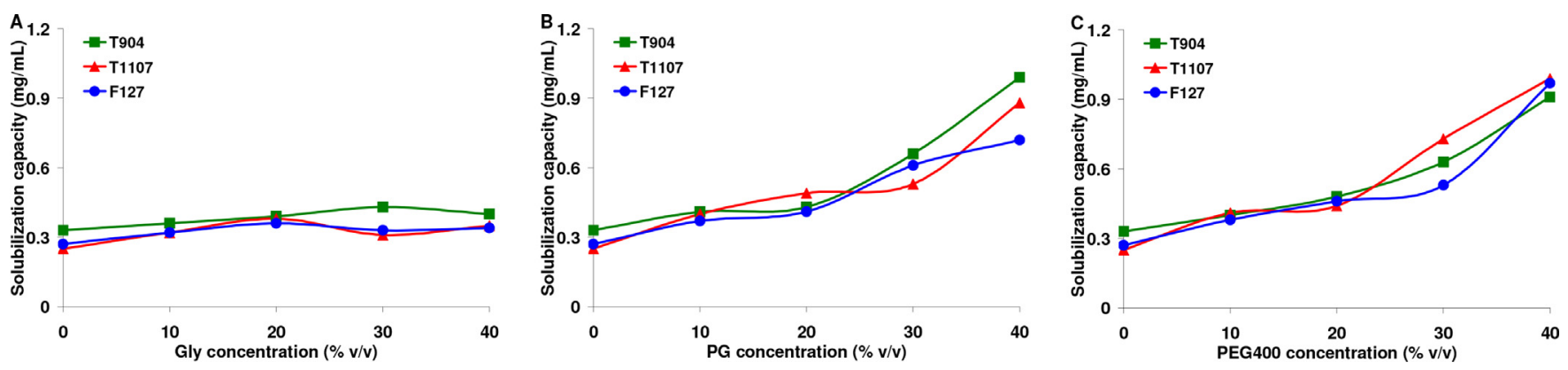

Fig. 3. Effect of the different cosolvents over the solubilization capacity of the copolymeric micellar dispersions. 
A

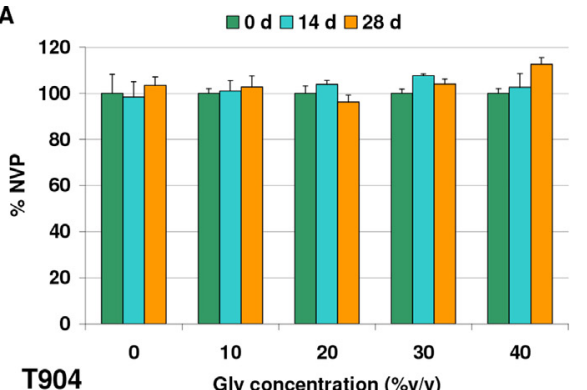

D

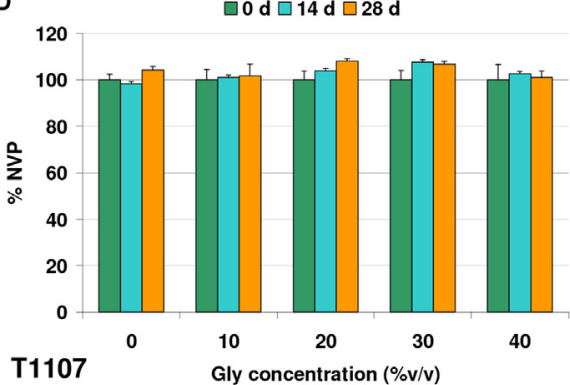

G

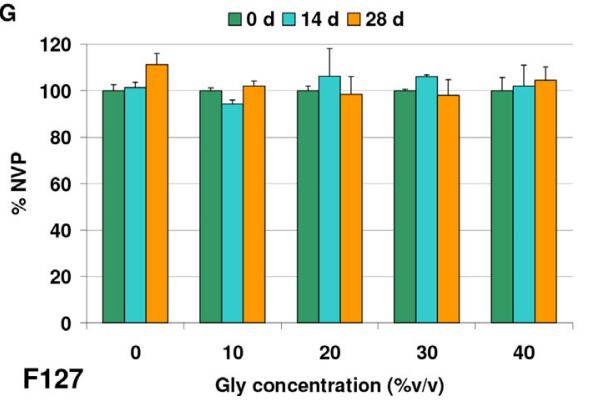

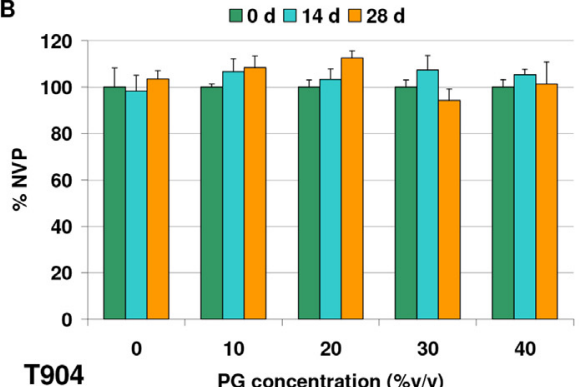

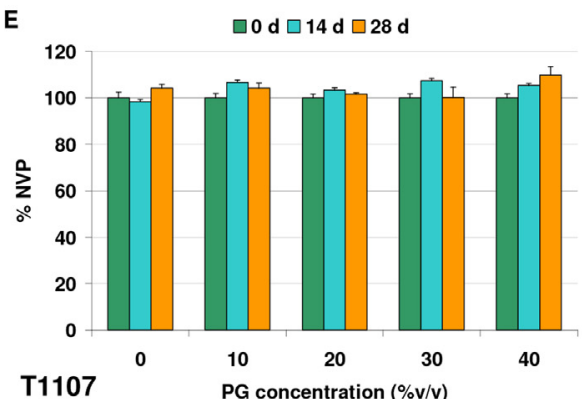

H

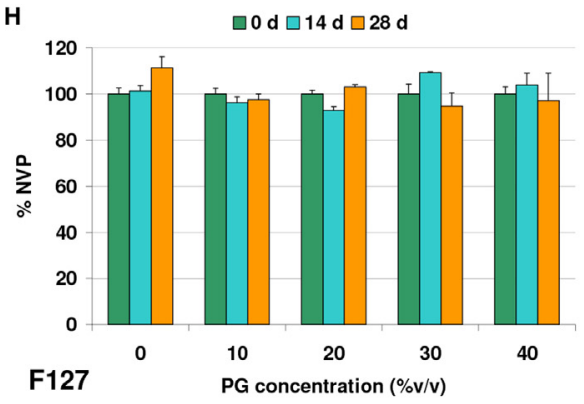

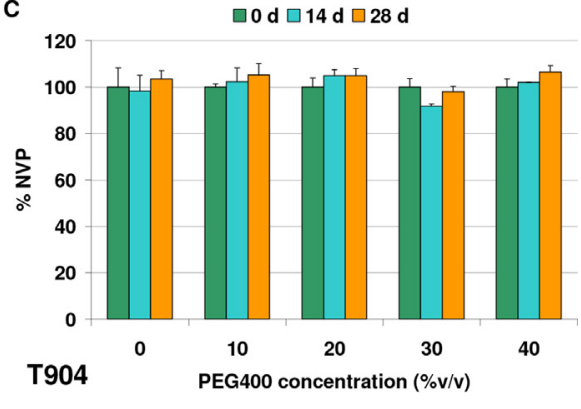

$\mathbf{F}$

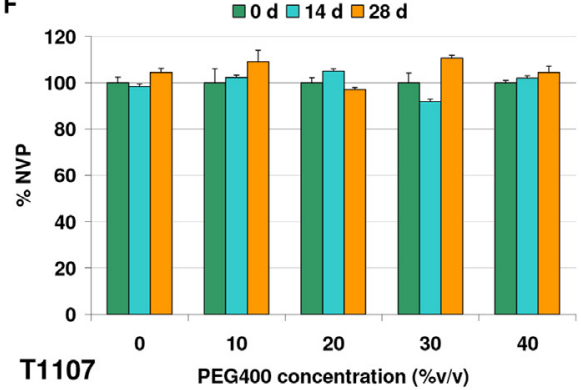

I

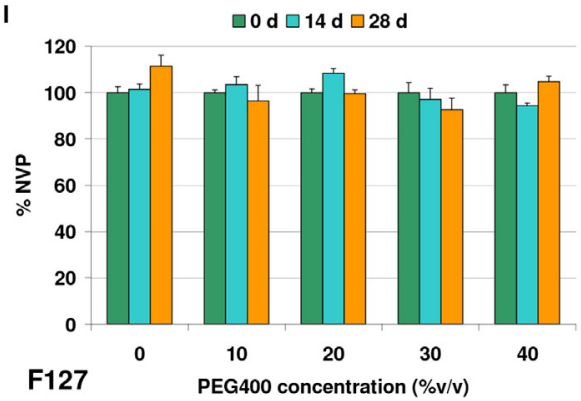

Fig. 4. NVP content (\%) in copolymeric systems without and with the addition of cosolvent $(0-40 \% \mathrm{v} / \mathrm{v})$ over $28 \mathrm{~d}$ at $25^{\circ} \mathrm{C}(n=3 \pm$ S.D. $)$.

showed values of 2.49 and $2.45 \mathrm{mg} / \mathrm{mL}$ as opposed to the corresponding sums of 1.67 and $1.69 \mathrm{mg} / \mathrm{mL}$. This synergistic effect could be explained in terms of a change in the micelle characteristics after cosolvent incorporation. In this case, PG and PEG400 could be associated with the micelle PEO-corona, providing a grater region of reduced polarity to improve NVP solubility in micelle/cosolvent systems [32]. However, this effect was not observed after Gly incorporation to the micellar dispersions. This result is probably related with the higher water-affinity of Gly in comparison with PG and PEG400 where strong Gly-water interactions could take place minimizing its association with the micellar corona. This effect was also observed in the DLS assay.

\subsection{Effect of NVP on the size of the aggregates}

The entrapment of drug molecules into the polymeric micelles may result in an increase of the micellar size due to the enlargement of the micellar hydrophobic core region [41]. Therefore, variations in the size could be attributed to the presence of NVP.

To evaluate the effect of NVP on the size of the aggregates, we choose the micellar systems optimized in terms of NVP concentration and with the smallest possible amount of cosolvents. In this case, the encapsulation of NVP produced a slight increase in micellar size. For T904 micelles with PG and PEG400, the presence of drug produced a minimal size increase from 60 to $65 \mathrm{~nm}$. For T1107 and
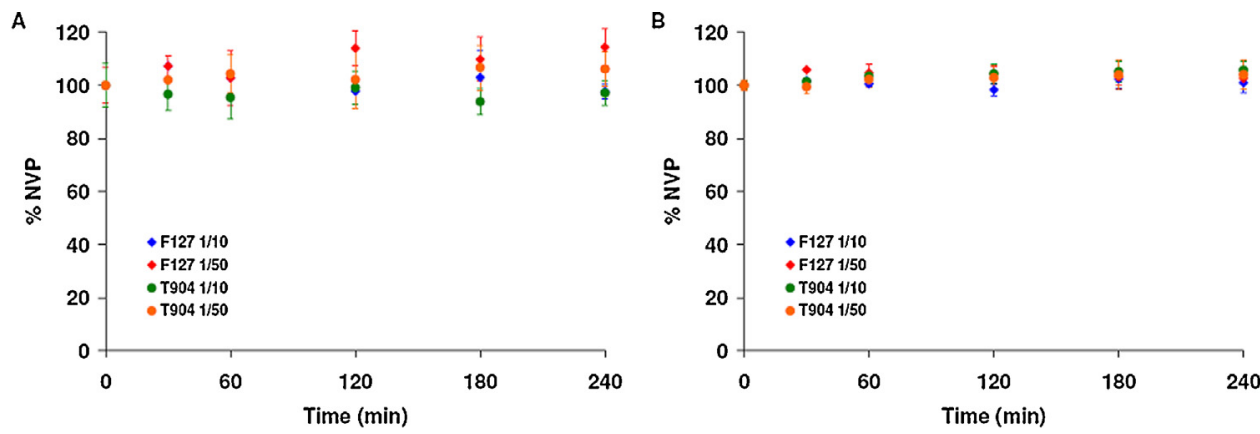

Fig. 5. Percentage of NVP in solutions of diluted $(1 / 10,1 / 50)$ drug-loaded polymeric micelles over $4 \mathrm{~h}$ at $37^{\circ} \mathrm{C}$. (A) pH 1.2 and $(\mathrm{B}) \mathrm{pH} 6.8\left(n=3 \pm \mathrm{S}^{\mathrm{D}} \mathrm{D}\right.$.). 
F127, we observed only an increase in the main population; being higher for the poloxamine (from 96 to $133 \mathrm{~nm}$ ) in comparison with the poloxamer (from 118 to $121 \mathrm{~nm}$ ). The first fraction (minor population) remained unchanged for both systems. These results are in good concordance with previously investigations $[21,41]$.

\subsection{Physical stability of the NVP-containing micelles}

In case of liquid formulations is very important to evaluate the physical stability of the systems because under regular storage conditions, the temperature fluctuations could modify the CMC value of the copolymer and lead to the dissociation of the aggregates and the drug precipitation. Saturated drug-loaded systems were prepared as it was previously describe, stored at room temperature and monitored for NVP content. All samples showed high stability over $28 \mathrm{~d}$; titer levels remained almost unchanged at approximately 90-100\% (Fig. 4) and no precipitates were observed.

Another relevant point to evaluate is the behavior of drugloaded micelles upon dilution in gastro and intestinal environment. In this way, we evaluated the stability of T904 and F127 EFVcontaining micelles with PG and PEG400 (1:1) 40\% v/v, diluted (1/10 and $1 / 50$ ) in both mediums. The drug concentration was monitored by UV-vis spectrophotometry over time at $37^{\circ} \mathrm{C}$. The stability of the systems may be affected upon dilution due to the dissociation of the micelles (for both poloxamers and poloxamines) and protonation of the central ethylenediamine molecule (only in the case of poloxamines). In this case, both systems were highly stable, regardless of the dilution and $\mathrm{pH}$ used as is shown in Fig. 5A and B. Results demonstrated that the NVP concentration remained above $90 \%$ up to $4 \mathrm{~h}$.

\subsection{In vitro NVP release}

To characterize the release profiles, T904 and F127 NVPcontaining micelles with PG and PEG400 (1:1) 40\% v/v were dialyzed against gastrointestinal-mimicking medium and the concentrations monitored over $6 \mathrm{~h}$ (Fig. 6). In general, NVP release profiles described a linear curve that was consistent with first-order kinetics with regression coefficient values of 0.9942 and 0.9994 for T904 and F127, respectively. As shown in Fig. 6, T904 and F127 NVPloaded systems released $83 \%$ and $81 \%$ of the drug encapsulated, respectively, at $6 \mathrm{~h}$.

\subsection{Oral pharmacokinetic studies}

The in vivo oral performance of NVP formulated in T904 and F127 micelles with PG and PEG400 (1:1) 40\% v/v was compared with (i) an extemporaneous suspension obtained by dispersing the content of a NVP tablet in a $0.5 \% \mathrm{w} / \mathrm{v}$ carboxymethylcellulose aqueous solution and (ii) the commercial suspension (Viramune ${ }^{\circledR}$ ). The first formulation is product of a conventional practice in the hospital pharmacy which presents the minimal amount of pharmaceutical additives while the second is the unique market formulation for pediatric use. This represents the main reason why we believe that it is clinically relevant the benchmark comparison to Viramune ${ }^{\circledR}$ and an extemporaneous suspension in animals. In this assay, we evaluated the following pharmacokinetic parameters: maximum plasma concentration $\left(C_{\max }\right)$, time to maximum plasma concentration $\left(t_{\max }\right)$, area under the curve between 0 and $24 \mathrm{~h}\left(\mathrm{AUC}_{0-24}\right)$ and plasma elimination half-life $\left(t_{1 / 2}\right)$ using Wistar rats at a dose of $8 \mathrm{mg} \mathrm{NVP} / \mathrm{kg}$. These parameters of NVP were obtained by noncompartmental analysis of plasma concentrations at selected time points. The pharmacokinetic curves of the NVP plasma concentration versus time after oral administration are presented in Fig. 7.

Initially, the pharmacokinetic parameters obtained for both control formulations (Viramune ${ }^{\circledR}$ and extemporaneous suspension)

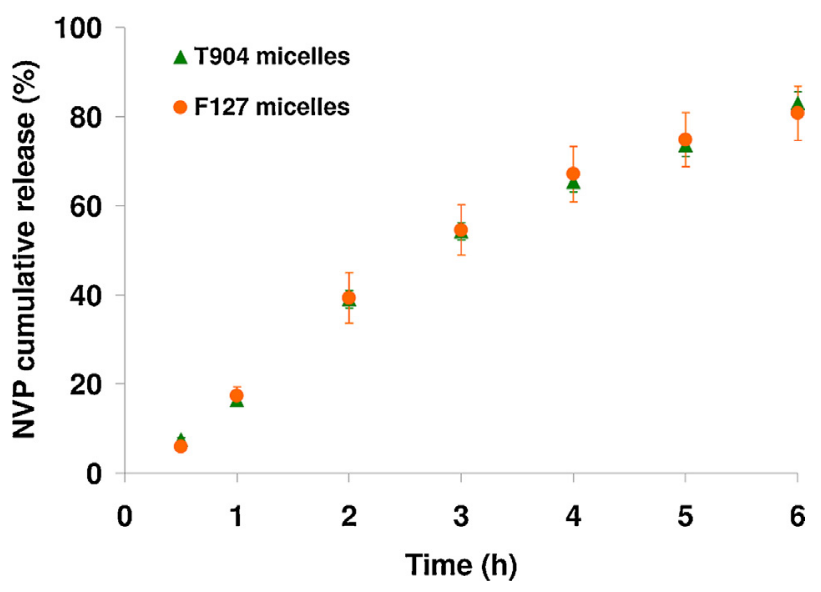

Fig. 6. In vitro drug release profiles of NVP-loaded micellar dispersions at $37^{\circ} \mathrm{C}$ over $6 \mathrm{~h}(n=3 \pm$ S.D. $)$.

were similar. The $C_{\max }$ and $\mathrm{AUC}_{0-24}$ values observed were $1999 \mathrm{ng} / \mathrm{mL}$ and $14.2 \mu \mathrm{g} / \mathrm{mL} / \mathrm{h}$ for NVP suspension and $1817 \mathrm{ng} / \mathrm{mL}$ and $15.9 \mu \mathrm{g} / \mathrm{mL} / \mathrm{h}$ for Viramune ${ }^{\circledR}$.

Secondly, we could see that micellar systems exhibited an increase of the $C_{\max }$ values to $3995 \mathrm{ng} / \mathrm{mL}$ (T904) and $2907 \mathrm{ng} / \mathrm{mL}$ (F127) from 1999 and $1817 \mathrm{ng} / \mathrm{mL}$ for the suspension and Viramune ${ }^{\circledR}$, respectively. This increment was statistically significant $(p<0.05)$ for NVP formulated in T904 micelles (Table 3). These results represented an increase of $220 \%$ and $160 \%$ respect to the market formulation Viramune ${ }^{\circledR}$. The difference between the $C_{\max }$ values for both micellar systems (T904 and F127) could be related with the size of the drug-loaded nanocarriers. It is well known that absorption through the intestinal mucosa depends on different structural and chemical factors such as the carrier size and its surface properties [42]. In the present work, the main difference between the nano-sized dispersions assayed is their hydrodynamic diameter (see Section 3.4). In this way, micelles with smaller size and greater surface area may present an extended diffusion through the mucus intestinal layer along with a faster intestinal absorption $[22,42]$. For this reason, the highest $C_{\max }$ value observed for T904 compared to F127 is probably due to the smaller size of T904 micellar system.

Also, as is shown in Fig. 7 and Table 3, polymeric micelles remarkably increase $\mathrm{AUC}_{0-24}$ values. There was a significant $(p<0.05)$ increase from 14.2 (extemporaneous suspension) to 30.2 (T904 micellar system) and $31.5 \mu \mathrm{g} / \mathrm{mL} / \mathrm{h}$ (F127 micellar system), representing an improvement of $213 \%$ and $222 \%$, respectively. In

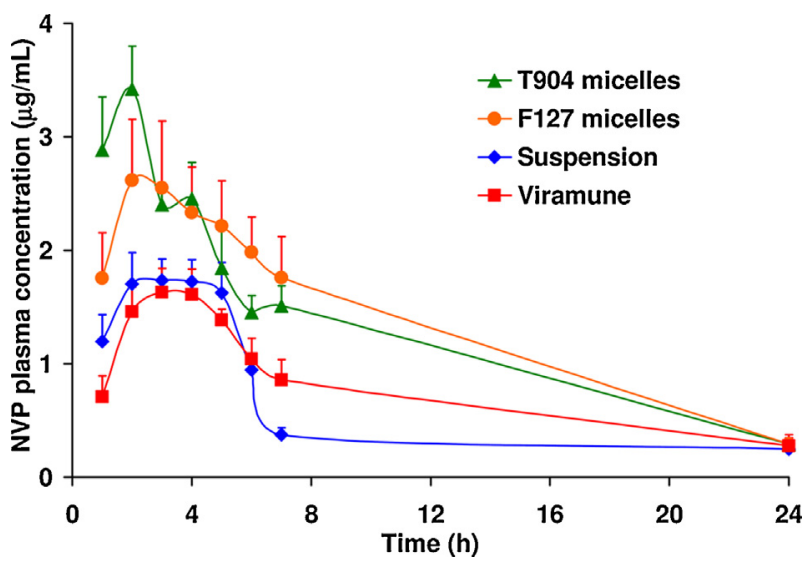

Fig. 7. Pharmacokinetic profile of extemporaneous suspension, Viramune ${ }^{\circledR}$ and NVP-loaded micellar systems. Data are expressed as mean \pm S.E. $(n=5)$. 
Table 3

Pharmacokinetic parameters of the different NVP formulations $(2 \mathrm{mg} / \mathrm{mL})$ administered orally. Results are expressed as mean \pm S.E. ( $n=5)$.

\begin{tabular}{|c|c|c|c|c|c|}
\hline Parameter & Units & Extemporaneous suspension & Viramune ${ }^{\circledR}$ & T904 micellar system & F127 micellar system \\
\hline$C_{\max }$ & $\mathrm{ng} / \mathrm{mL}$ & $1999 \pm 243$ & $1817 \pm 186$ & $3995 \pm 287^{*, * *}$ & $2907 \pm 548$ \\
\hline$t_{\max }$ & h & $3.0 \pm 0.7$ & $2.5 \pm 0.3$ & $3.0 \pm 0.6$ & $3.8 \pm 0.6$ \\
\hline AUC $_{0-24}$ & $\mu \mathrm{g} / \mathrm{mL} / \mathrm{h}$ & $14.2 \pm 1.3$ & $15.9 \pm 3.7$ & $30.2 \pm 3.6^{*, * *}$ & $31.5 \pm 6.4^{*}$ \\
\hline$t_{1 / 2}$ & $\mathrm{~h}$ & $10.1 \pm 1.5$ & $7.1 \pm 1.8$ & $8.1 \pm 2.1$ & $6.5 \pm 0.5$ \\
\hline$F_{r}$ & $\%$ & 100.0 & 112.0 & 212.7 & 221.8 \\
\hline
\end{tabular}

$C_{\max }$ : Maximum plasma concentration.

$t_{\max }$ : Time to maximum plasma concentration.

$\mathrm{AUC}_{0-24}$ : Area under the curve between 0 and $24 \mathrm{~h}$

$t_{1 / 2}$ : Plasma elimination half-life.

$F_{r}$ : Relative oral bioavailability.

* $p<0.05$ vs. extemporaneous suspension.

$p<0.05$ vs. Viramune ${ }^{\circledR}$.

case of Viramune ${ }^{\circledR}$ there was also an improvement on $\mathrm{AUC}_{0-24}$ values of $190 \%$ and $198 \%$ for T904 and F127 micellar dispersions, respectively, being statistically $(p<0.05)$ different only for T904 formulation (Table 3). This data represented an increase on NVP oral bioavailability of 2.1 (T904) and 2.2 (F127)-folds respect the extemporaneous suspension (reference). These results demonstrated that the inclusion of the poorly water soluble NVP into the polymeric micelles remarkably improved the drug oral bioavailability.

The $t_{\max }$ values remain almost unchanged for every sample assayed (Table 3 ). This result was expected since the micellar formulation was not developed as a system for sustain drug release. Thereafter no variation on NVP oral rate of absorption was expected. Furthermore, the half-life of NVP was similar comparing all formulations, suggesting that the drug elimination is not modified by the micellar systems.

Finally, the results obtained for the pharmacokinetic analysis of NVP plasma levels after oral administration are in good concordance with previously investigations where hydrophobic drugs-loaded micellar systems present better oral bioavailability compared to extemporaneous suspensions and commercial formulations $[38,43]$.

In terms of formulation safety, this novel aqueous micellar formulation contains not only PEO-PPO-PEO copolymers but also pharmaceutical cosolvents. On one hand, poloxamers and poloxamines are triblock copolymers composed of water-soluble PEO and PPO as hydrophobic domain. Due to their excellent biocompatibility [44] and their capacity to form thermoreversible gels, these copolymers have been one of the most studied biomaterials for the development of (i) injectable matrices $[45,46]$ and (ii) novel drug delivery systems for adults and children $[9,22,47,48]$. Moreover, F127 has been approved by Food and Drug Administration (FDA) and it is encoded in the Handbook of Pharmaceutical Excipients [49]. In this framework, NVP-loaded PEO-PPO-PEO micelles represent a novel approach to enhance pediatric HAART employing these biocompatible PEO-PPO-based copolymers. On the other hand, our micellar formulation also involved the addition of PG and PEG400 (40\% v/v, 1:1). In this case, both cosolvents are encoded in the Handbook of Pharmaceutical Excipients [49]. The European Medicines Agency (EMA) has established a daily PG parental and oral administration limit of 200 and $400 \mathrm{mg} / \mathrm{kg}$ for children and adults, respectively. However, more clinical pediatric pharmacokinetic data is needed in order to determinate if specific limits for different age groups are required [50]. According to the NVP shortterm treatment ( 6 weeks) proposed by WHO for neonates, the administration of PG would be lower than the daily oral limit recommended by the EMA if the aqueous micellar formulation (NVP $2 \mathrm{mg} / \mathrm{mL}, 5 \mathrm{mg} / \mathrm{d}$ ) developed in the present investigation is employed. Finally, PEGs have been used in different pharmaceutical formulations for parenteral, oral, ophthalmic, topical and rectal administration [49]. Particularly, PEG400 has been classified as an "inactive ingredient" by FDA [51] and its use has been approved in different commercially available products [52].

\section{Conclusion}

In this work, PEO-PPO-PEO polymeric micelles (Tetronic ${ }^{\circledR} 904$, 1107 and Pluronic ${ }^{\circledR}$ F127) with the addition of three cosolvents of pharmaceutical interest (Gly, PG and PEG400) over a wider range of concentrations $(0-40 \% \mathrm{v} / \mathrm{v})$ were successfully employed for the solubilization of NVP for the first time in this type of nanocarriers. The addition of all cosolvents to micellar dispersions produced an increase in the micellar size. PG and PEG400 resulted more effective than Gly to increase apparent aqueous solubility of NVP. These results showed that PG and PEG400 are the cosolvents appropriate to prepare an optimized nanocarrier in terms of NVP concentration (clinical doses) and with the smallest possible amount of cosolvents, using a mixture of them $(40 \% \mathrm{v} / \mathrm{v}$, ratio $1: 1)$. Finally, the comparative preclinical evaluation of the NVPloaded micellar formulation with an extemporaneous suspension and with the pediatric commercially available Viramune ${ }^{\circledR}$ confirmed the improved oral bioavailability of the nano-sized micellar carrier.

Based on these results, it can be concluded that our novel NVP aqueous formulation should be considered as an effective antiretroviral drug delivery system for prevent HIV/AIDS mother-to-child transmission.

\section{Acknowledgements}

Authors thank the University of Buenos Aires (Grant UBACyT 20020100300088 and 20020120200058 ). MAM is supported by postdoctoral scholarship of CONICET and EB by the PFDT fellowship of the ANPCyT (FONARSEC PICT-PRH 2008-00315), Argentina. CT and DAC are partially supported by CONICET, Argentina.

\section{References}

[1] http://www.who.int/mediacentre/factsheets/fs360/en/ (accessed May 2014).

[2] G.A. Weinberg, Birth 27 (2000) 199.

[3] F.L.I. Morfaw, L. Thabane, L.C.E. Mbuagbaw, P.N. Nana, Syst. Rev. 1 (2012) 13

[4] S. Nesheim, L.F. Harris, M. Lampe, Curr. Opin. HIV AIDS 8 (2013) 447.

[5] http://www.unaids.org/en/media/unaids/contentassets/documents/ epidemiology/2012/gr2012/20121120_UNAIDS_Global_Report_2012_with _annexes_en.pdf (accessed September 2013).

[6] http://www.avert.org/motherchild.htm (accessed September 2013).

[7] http://www.avert.org/pmtct-guidelines.htm (accessed September 2013).

[8] Six Week Extended-Dose Nevirapine (SWEN) Study Team, Lancet 372 (2008) 300.

[9] D.A. Chiappetta, C. Hocht, A. Sosnik, Curr. HIV Res. 8 (2010) 223.

[10] A. Bowles, J. Keane, T. Ernest, D. Clapham, C. Tuleu, Int. J. Pharm. 395 (2010) 37.

[11] R. L'homme, A. Warris, D. Burger, Curr. Opin. HIV AIDS 2 (2007) 405.

[12] M. Lindenberg, S. Kopp, J.B. Dressman, Eur. J. Pharm. Biopharm. 58 (2004) 265

[13] N. Stieger, M.R. Caira, W. Liebenberg, L.R. Tiedt, J.C. Wessels, M.M. De Villiers, Crystal Growth Des. 10 (2010) 3859. 
[14] R. Chadha, P. Arora, A. Saini, D.S. Jain, AAPS PharmSciTech 11 (2010) 1328.

[15] V.E. Rexroad, T.L. Parsons, F.M. Hamzeh, X. Li, M.L. Dreyfuss, P.D. Stamper, R.H. Gray, J. Acquir. Immune Defic. Syndr. 43 (2006) 373.

[16] F. Buontempo, E. Bernabeu, R.J. Glisoni, E. Quiroga, C. Bregni, D.A. Chiappetta, Farm. Hosp. 34 (2010) 293.

[17] R. Chadha, P. Arora, S. Gupta, D.S. Jain, J. Therm. Anal. Calorim. 105 (2011) 1049.

[18] K.M. Lokamatha, A. Bharathi, S.M. Shanta Kumar, N. Rama Rao, Int. J. Pharm. Pharm. Sci. 2 (2010) 169.

[19] M.C. Sharma, S. Sharma, Int. J. PharmTech Res. 3 (2011) 144.

[20] A. Chudasama, V. Patel, M. Nivsarkar, K. Vasu, C. Shishoo, Int. J. PharmTech Res. $3(2011) 1159$.

[21] D.A. Chiappetta, C. Alvarez-Lorenzo, A. Rey-Rico, P. Taboada, A. Concheiro, A. Sosnik, Eur. J. Pharm. Biopharm. 76 (2010) 24.

22] D.A. Chiappetta, C. Hocht, C. Taira, A. Sosnik, Biomaterials 32 (2011) 2379.

[23] M.A. Moretton, C. Höcht, C. Taira, A. Sosnik, Nanomedicine (Lond) (2014), http://dx.doi.org/10.2217/nnm.13.154.

[24] D.A. Chiappetta, A. Sosnik, Eur. J. Pharm. Biopharm. 66 (2007) 303.

[25] T. Nivaggioli, B. Tsao, P. Alexandridis, T.A. Hatton, Langmuir 11 (1995) 119.

[26] Y. Kadam, U. Yerramilli, A. Bahadur, P. Bahadur, Colloids Surf. B 83 (2011) 49.

[27] J. Dong, B.Z. Chowdhry, S.A. Leharne, Colloids Surf. A 212 (2003) 9.

[28] W. He, L.F. Fan, Q. Du, B. Xiang, C.L. Li, M. Bai, Y.Z. Chang, D.Y. Cao, Chem. Pharm. Bull. 57 (2009) 122

[29] L.D. Aimone, Curr. Protoc. Pharmacol. 30 (2005) 1.

[30] T. Liu, G. Xu, H. Gong, J. Pang, F. He, Langmuir 27 (2011) 9253.

[31] P. Jain, S.H. Yalkowsky, Int. J. Pharm. 342 (2007) 1.

[32] C.P. Oliveira, M.E.N.P. Ribeiro, N.M.P.S. Ricardo, T.V. de, P. Souza, C. Lima Moura, C. Chaibundit, S.G. Yeates, K. Nixon, D. Attwood, Int. J. Pharm. 421 (2011) 252

[33] N.M.P.S. Ricardo, N.M.P.S. Ricardo, F. de, M.L.L. Costa, F.W.A. Bezerra, C. Chaibundit, D. Hermida-Merino, B.W. Greenland, S. Burattini, I.W. Hamley, S. Keith Nixon, S.G. Yeates, J. Colloid Interface Sci. 368 (2012) 336.

[34] R. Sanan, R.K. Mahajan, Colloids Surf. A 433 (2013) 145
[35] A.K. Nayak, P.P. Panigrahi, ISRN Phys. Chem. 2012 (2012) 1.

[36] B. Sarkar, V. Ravi, P. Alexandridis, J. Colloid Interface Sci. 390 (2013) 137

[37] J. Gonzalez-Lopez, C. Alvarez-Lorenzo, P. Taboada, A. Sosnik, I. Sandez-Macho, A. Concheiro, Langmuir 24 (2008) 10688.

[38] D.A. Chiappetta, C. Hocht, C. Taira, A. Sosnik, Nanomedicine 5 (2010) 11

[39] P.R. Sathesh Babu, C.V.S. Subrahmanyam, J. Thimmasetty, R. Manavalan, K. Valliappan, S.A. Kedarnath, Dhaka University J. Pharm. Sci. 7 (2008) 119.

[40] M. Crothers, N.M.P.S. Ricardo, F. Heatley, S.K. Nixon, D. Attwood, C. Booth, Int J. Pharm. 358 (2008) 303.

[41] S.S. Kulthe, N.N. Inamdar, Y.M. Choudhari, S.M. Shirolikar, L.C. Borde, V.K. Mourya, Colloids Surf. B 88 (2011) 691

[42] G. Gaucher, P. Satturwar, M.-C. Jones, A. Furtos, J.-C. Leroux, Eur. J. Pharm. Biopharm. 76 (2010) 147.

[43] H. Yu, D. Xia, Q. Zhu, C. Zhu, D. Chen, Y. Gan, Eur. J. Pharm. Biopharm. 85 (2013) 1325.

[44] L.E. Bromberg, E.S. Ron, Adv. Drug Deliv. Rev. 31 (1998) 197.

[45] S. Qian, Y.C. Wong, Z. Zuo, Int. J. Pharm. (2014), http://dx.doi.org/10.1016/ j.ijpharm.2014.04.015.

[46] M. Plotkin, S.R. Vaibavi, A.J. Rufaihah, V. Nithya, J. Wang, Y. Shachaf, T. Kofidis, D. Seliktar, Biomaterials 35 (2014) 1429.

[47] W. Zhang, Y. Shi, Y. Chen, J. Hao, X. Sha, X. Fang, Biomaterials 32 (2011) 5934.

[48] L. Chen, X. Sha, X. Jiang, Y. Chen, Q. Ren, X. Fang, Int. J. Nanomed. 8 (2013) 73.

[49] R.C. Rowe, P.J. Sheskey, M.E. Quinn (Eds.), Handbook of Pharmaceutical Excipients, 6th ed., Pharmaceutical Press and American Pharmacists Association, London-Chicago, 2009.

[50] http://www.ema.europa.eu/docs/en_GB/document_library/Report/2014/03/ WC500163989.pdf (accessed May 2014).

[51] http://www.accessdata.fda.gov/scripts/cder/iig/getiigWEB.cfm (accessed May 2014).

[52] http://www.fda.gov (accessed May 2014). 